\title{
An Overview of Strobilurin Fungicide Degradation:Current Status and Future Perspective
}

\author{
Yanmei Feng ${ }^{1,2}$, Yaohua Huang ${ }^{1,2}$, Hui Zhan ${ }^{1,2}$, Pankaj Bhatt ${ }^{1,2}$ and Shaohua Chen 1,2* \\ 'State Key Laboratory for Conservation and Utilization of Subtropical Agro-bioresources, Guangdong Laboratory for \\ Lingnan Modern Agriculture, Integrative Microbiology Research Centre, South China Agricultural University, Guangzhou, \\ China, ${ }^{2}$ Guangdong Province Key Laboratory of Microbial Signals and Disease Control, Guangzhou, China
}

\section{OPEN ACCESS}

Edited by:

Eric Altermann,

AgResearch, New Zealand

Reviewed by:

Xiaomei SU,

Zhejiang Normal University, China

Nuno Pereira Mira,

University of Lisbon, Portugal

${ }^{*}$ Correspondence:

Shaohua Chen

shchen@scau.edu.cn

Specialty section:

This article was submitted to

Microbiotechnology,

a section of the journal

Frontiers in Microbiology

Received: 19 April 2019

Accepted: 25 February 2020

Published: 12 March 2020

Citation:

Feng $Y$, Huang $Y$, Zhan $H$, Bhatt $P$ and Chen S (2020) An Overview of Strobilurin Fungicide

Degradation:Current Status and Future Perspective.

Front. Microbiol. 11:389.

doi: 10.3389/fmicb.2020.00389
Strobilurin fungicides have been widely used in agricultural fields for decades. These pesticides are designed to manage fungal pathogens, although their broad-spectrum mode of action also produces non-target impacts. Therefore, the removal of strobilurins from ecosystems has received much attention. Different remediation technologies have been developed to eliminate pesticide residues from soil/water environments, such as photodecomposition, ozonation, adsorption, incineration, and biodegradation. Compared with conventional methods, bioremediation is considered a cost-effective and ecofriendly approach for the removal of pesticide residues. Several strobilurindegrading microbes and microbial communities have been reported to effectively utilize pesticide residues as a carbon and nitrogen source. The degradation pathways of strobilurins and the fate of several metabolites have been reported. Further indepth studies based on molecular biology and genetics are needed to elaborate their role in the evolution of novel catabolic pathways and the microbial degradation of strobilurins. The present review summarizes recent progress in strobilurin degradation and comprehensively discusses the potential of strobilurin-degrading microorganisms in the bioremediation of contaminated environments.

Keywords: strobilurin, ecotoxicity, biodegradation, bioremediation, transformation, degradation pathways

\section{INTRODUCTION}

Strobilurin fungicides are globally used to combat white mold, rot, early and late leaf spot, rusts and rice blast (Bartett et al., 2001; FAO Meeting, 2008). Mushrooms (Basidiomycetes) are natural sources of strobilurins, and the first natural strobilurin compound, Strobilurin-A, was originally isolated from the mushroom Strobilurus tenacellus by Anke et al. (1977). The first patent for a strobilurin fungicide (azoxystrobin) was introduced in the German market in 1996 (Sauter et al., 1999; Bartett et al., 2001). Subsequently, a series of strobilurin fungicides, including azoxystrobin, pyraclostrobin, fluoxastrobin, kresoxim-methyl, trifloxystrobin, picoxystrobin, mandestrobin, and metominostrobin, were developed and marketed (Rodrigues et al., 2013; Khandelwal et al., 2014). Structurally, the presence of toxiphoric (E)- $\beta$-methoxyacrylate group is the main feature of strobilurin fungicides (Balba, 2007), as presented in Figure 1. Strobilurin fungicides are also referred as $\mathrm{Q}_{0} \mathrm{I}$ fungicides because of their unique mechanism of action. They specifically bind to the quinol oxidation $\left(\mathrm{Q}_{0}\right)$ site of cytochrome $b$ to inhibit mitochondrial respiration. This binding blocks electron transfer between cytochrome $\mathrm{b}$ and cytochrome $\mathrm{cl}$ and inhibits the synthesis of 
A zoxystrob in

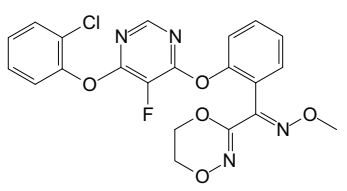

Fluoxastrobin

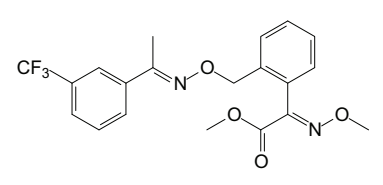

Trifloxystrob in

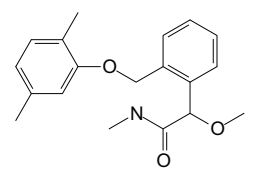

Mandestrobin

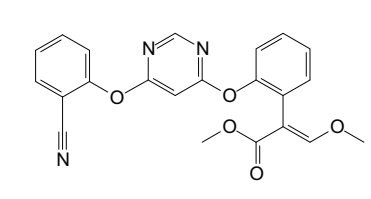

Pyraclostrobin

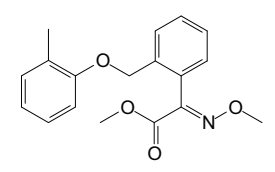

$\mathrm{K}$ resox im -m ethy 1

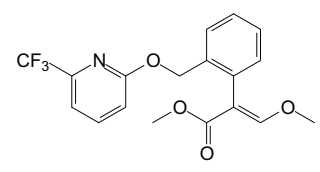

Picoxystrobin

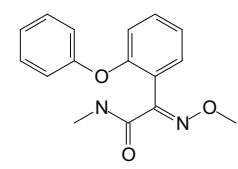

Metominostrobin

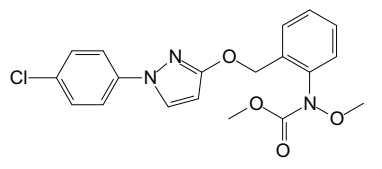

FIGURE 1 | Molecular structures of strobilurins.

nicotinamide adenine dinucleotide (NADH) oxidation and the mitochondrial membrane protein adenosine triphosphate (ATP) (Hnátová et al., 2003; Isamu and Makoto, 2005; Balba, 2007; Rodrigues et al., 2013). The fungicidal action of strobilurins is novel and non-target specific.

Strobilurins present broad-spectrum, rapid and highly efficient germicidal activities, are cost effective and rapidly degrade during plant metabolism, and these benefits have contributed to the large-scale use of these fungicides. However, environmental contamination and non-target toxicity due to the long-term use of strobilurins has raised serious public health concerns. For instance, according to the European Food Safety Authority (EFSA), azoxystrobin is frequently found in foodstuffs (EFSA, 2010). Environmental concentrations of azoxystrobin higher than the Regulatory Acceptable Concentration (RAC) have been found in ecosystems, which poses a serious risk to soil organisms, aquatic organisms, and mammals (Warming et al., 2009; Dijksterhuis et al., 2011; Liu et al., 2013; Mostafalou and Abdollahi, 2013; Rodrigues et al., 2013; Regueiro et al., 2015; Li et al., 2016; Pearson et al., 2016; Zubrod et al., 2019). In addition, strobilurins are susceptible to resistance because they act on one specific site of fungal pathogens. Several resistance genes from strobilurin-treated fungi have been reported (Zheng and Köeller, 1997; Fisher et al., 2004; Walker et al., 2009; Piszczek et al., 2017). These reports suggested that strobilurins can potentially cause long-term adverse effects to the ecosystem.
Strobilurins can be degraded either through biotic or abiotic approaches, such as incineration, photodecomposition, adsorption, and biodegradation. Compared with physicochemical methods, the microbial degradation of pesticide residues is emerging as an efficient "green" strategy (Chen et al., 2011; Harms et al., 2011; Xiao et al., 2015; Arora et al., 2017; Cycoń et al., 2017; Yang et al., 2018). Several reports have focused on the isolation and characterization of strobilurin-degrading microbes and microbial communities (Lopes et al., 2010; Clinton et al., 2011; Howell et al., 2014; Bacmaga et al., 2015; Chen et al., 2018). These microbes include Bacillus, Pseudomonas, Klebsiella, Stenotrophomonas, Arthrobacter, Rhodanobacter, Cupriavidus, and Aphanoascus. The metabolic pathways of strobilurins and the fate of several metabolites have been reported. However, there is a limited number of studies on strobilurin-degrading enzymes and the corresponding genes in microorganisms. In addition, few reviews have focused on the mechanisms and degradation pathways of strobilurins. In this review, we aim to summarize strobilurin degradation mechanisms and analyze the bioremediation potential of strobilurin-degrading microorganisms in contaminated soil/water environments.

\section{PHYSICOCHEMICAL TRANSFORMATION OF STROBILURINS}

Strobilurin residues remain in the air, soil, or water after field applications, and the physicochemical properties of the associated environment affect the behavior and distribution of these residues (Rodrigues et al., 2013). Pesticide interacts with organic or mineral constituents as it reaches the soil and undergoes chemical and biological transformation (Bending et al., 2006). Generally, strobilurin compounds easily degrade in plants, animals, soil, and water (Lee et al., 1999; Balba, 2007). Joseph (1999) explored the abiotic degradation of azoxystrobin in three different soils and reported that azoxystrobin was photodegraded at a half-life $\left(t_{1 / 2}\right)$ of less than 14 days under field conditions while the half-life of azoxystrobin was approximately 8-12 weeks under dark aerobic conditions. The study also revealed that hydrolysis of the ester moiety is the major metabolic pathway of azoxystrobin. Boudina et al. (2007) studied the photochemical behavior of azoxystrobin in aqueous solutions and revealed that multiple parallel reaction pathways occur during its phototransformation. These pathways include

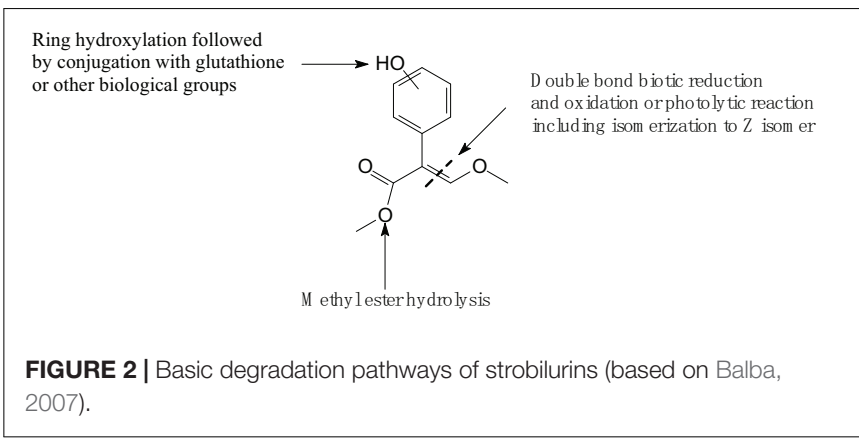




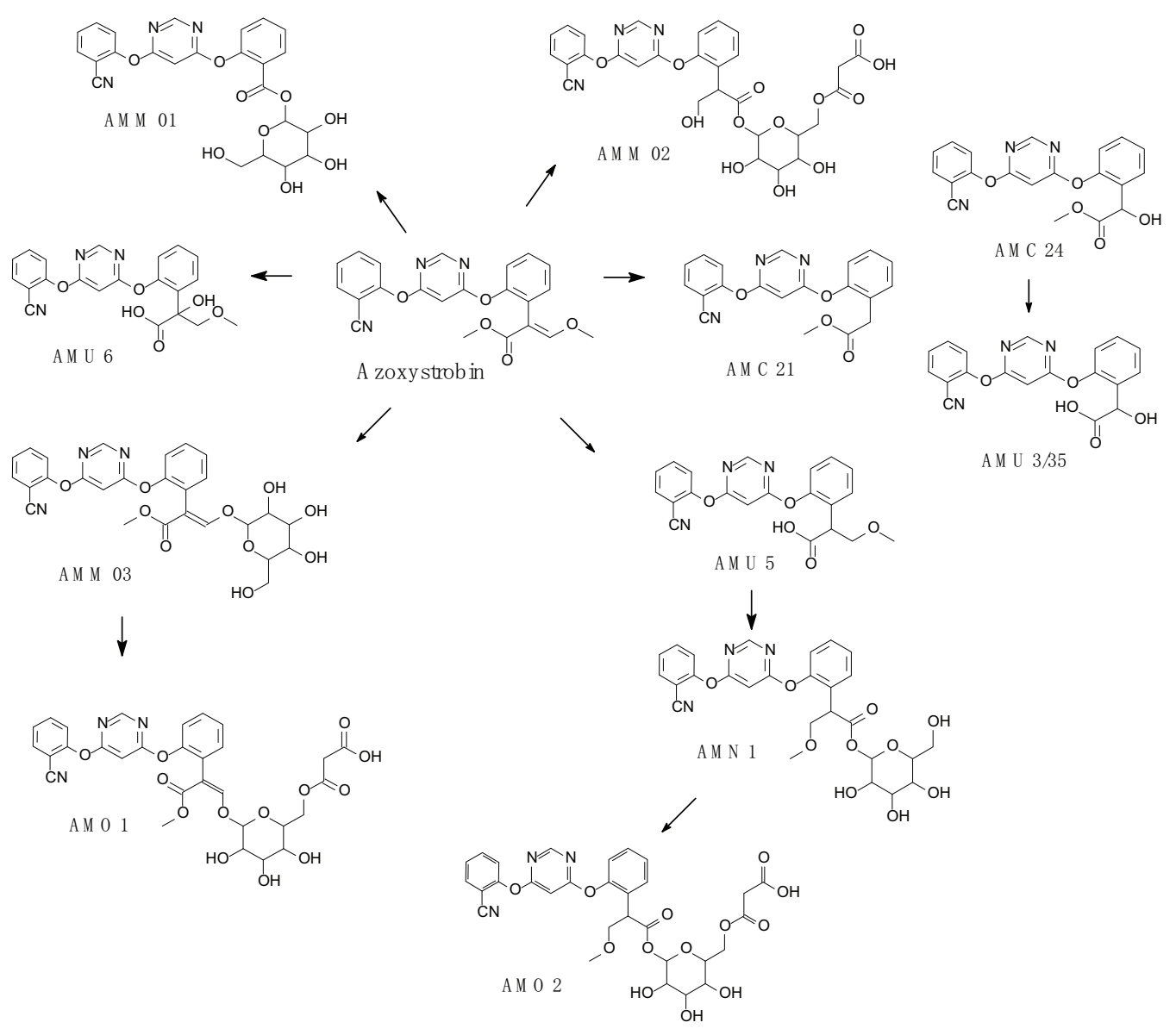

FIGURE 3 | Proposed degradation pathway of azoxystrobin in Brassica species (based on Bauer et al., 2018).

photoisomerization $(E \rightarrow Z)$, acrylate double bond cleavage, photohydrolysis of nitrile group and methyl ester, and phenol and oxidative cleavage of acrylate double bonds after the cleavage of aromatic rings. The results also showed that azoxystrobin absorbs light at higher wavelengths $(290 \mathrm{~nm})$ in aqueous environments, which facilitate its photodegradation. Singh et al. (2010) explored the metabolism of (14) C-azoxstrobin under aqueous conditions at $\mathrm{pH} 4,7$, and 9 and identified metabolite R234886 as (E)-2-\{2-[6-(2-cyano-phenoxy) pyrimidin-4-yloxy] phenyl\}-3-methoxyacrylic acid, which is the main metabolite of azoxystrobin. Compared to acidic ( $\mathrm{pH} 4)$ or neutral ( $\mathrm{pH} 7$ ) conditions, metabolite formation occurred in larger quantities and comparatively faster under alkaline $(\mathrm{pH} 9)$ conditions. Chastain et al. (2013) found that the photochemical reactivity of azoxystrobin was enhanced as the solvent polarity decreased. This phenomenon indicates that the accumulation of azoxystrobin tends to occur inside the cuticle, where it is photodegraded, or at the surface of crop leaves.

Azoxystrobin metabolism is similar to the degradation of methoxyiminoacetate (Balba, 2007) and the fate of trifloxystrobin in plants and kresoxim-methyl in soils, plants, and rats. Khandelwal et al. (2016) investigated the persistence of kresoximmethyl at different temperatures, $\mathrm{pH}$, atmospheric $\mathrm{CO}_{2}$ levels

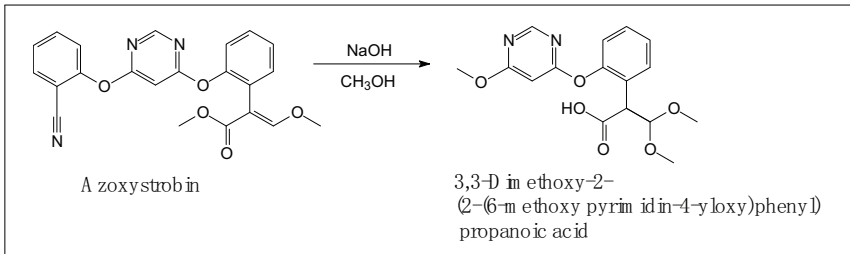

FIGURE 4 | Proposed degradation pathway of azoxystrobin via the hydrolysis reaction (based on Zhang et al., 2011).

and light in aqueous conditions and revealed that it readily forms acid metabolites. The study emphasized that abiotic factors have significant effects on the dissipation of kresoxim-methyl under aqueous conditions. Similarly, photolysis has also been reported as the main degradation pathway of trifloxystrobin under field conditions, and the number of sunshine hours is the key influencing factor for the photolysis process (Wang et al., 2015). Trifloxystrobin residue was found in tomato, whereas its metabolite trifloxystrobin acid was observed in soil (Wang et al., 2014).

Reddy et al. (2013) reported that the organic matter content, microbial population and soil moisture affected 


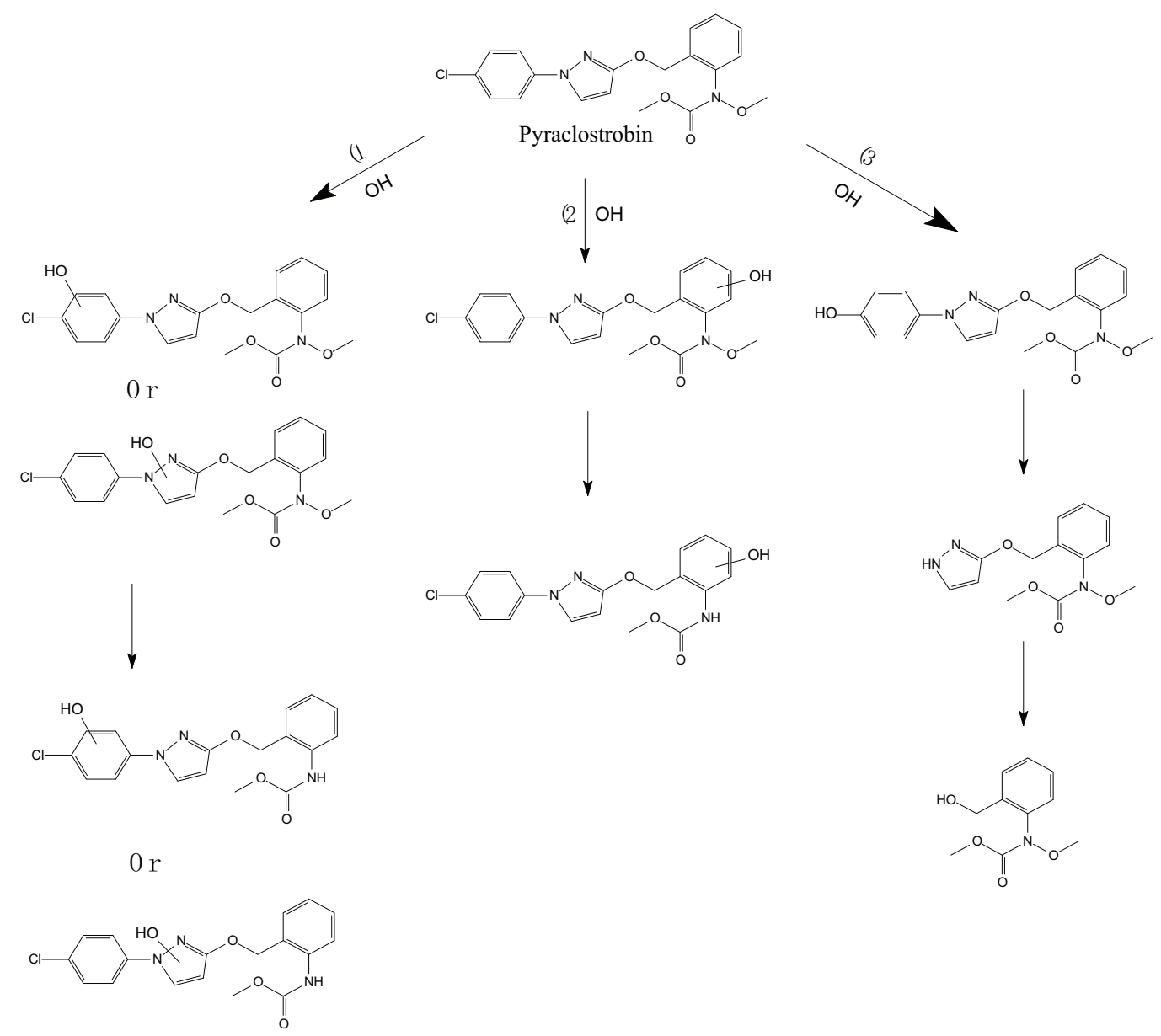

FIGURE 5 | Proposed degradation pathway of pyraclostrobin via the photocatalysis reaction (based on Lagunas-Allué et al., 2012).

the dissipation of pyraclostrobin, and their results showed the more rapid dissipation of pyraclostrobin under wet air conditions compared with dry conditions; moreover, the most rapid pyraclostrobin dissipation occurred in sludgeamended soil ( $t_{1 / 2} 9.2$ days). Contrary to Reddy et al. (2013); Zeng et al. (2019) found that the degradation rate of pyraclostrobin was faster in aqueous solution under the UV photolysis reaction compared with that under sunlight. Unlike natural strobilurins that have the conventional methoxyacrylate or methoxyiminoacetate structure, mandestrobin possesses a unique methoxyacetamide moiety and showed resistance to alkaline hydrolysis (Adachi et al., 2018).

\section{ECO-TOXICITY OF STROBILURINS}

The excessive and long-term use of strobilurins has adversely affected ecosystems. Hydrolytically stable azoxystrobin presents low solubility $\left(6.7 \mathrm{mg} \cdot \mathrm{L}^{-1}\right.$ at $\left.20^{\circ} \mathrm{C}\right)$ at $\mathrm{pH}$ values between 4 and 9, which demonstrates its potential risk to water quality (Deb et al., 2010; EFSA, 2010; Singh et al., 2010). Many researchers have discovered that azoxystrobin is not only toxic to target fungi but also to non-target organisms. Friberg-Jensen et al. (2010) investigated the sub-lethal toxicity of azoxystrobin on different physiological parameters of eggcarrying Daphnia magna (such as the heart, filtering limbs, mandibles, and focal spine), and they concluded that after $24 \mathrm{~h}$ of activity, all response parameters decreased except the focal spine at an azoxystrobin concentration of $500 \mu \mathrm{g} \cdot \mathrm{L}^{-1}$. DNA damage was observed in earthworms (Eisenia fetida) after azoxystrobin treatment (Han et al., 2014). The genotoxic effects of chronic and acute azoxystrobin concentrations in the erythrocytes of early life stages of brown trout Salmo trutta fario were assessed. The results highlighted the genotoxic threat to freshwater fish in azoxystrobin-contaminated rivers (Bony et al., 2008). Jia et al. (2018) also investigated the effects of azoxystrobin and picoxystrobin on the embryonic development and enzyme activity of zebrafish (Danio rerio). Their results indicated that both azoxystrobin and picoxystrobin caused dose- and time-dependent effects on embryonic development. Evaluations of the effects of azoxystrobin on biological activity in soil revealed that it changes microbial biodiversity by inhibiting the growth of organotrophic bacteria, actinomycetes, and fungi (Bacmaga et al., 2015). 


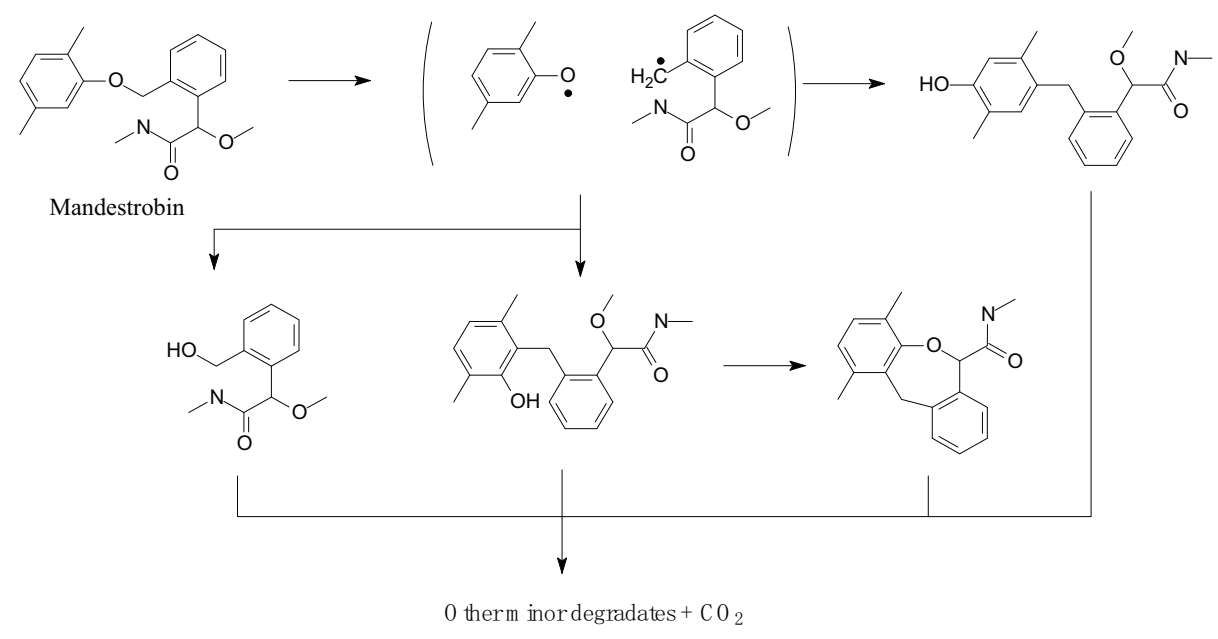

FIGURE 6 | Proposed degradation pathway of mandestrobin (based on Adachi et al., 2018).

Strobilurins were once considered less toxic to mammals (Bartlett et al., 2002); however, several authors have highlighted that scientific interpretations of their toxicity were limited because of gaps in the toxicological endpoints of fungicides (Battaglin et al., 2011). The toxicity of kresoxim-methyl and pyraclostrobin to the primary culture of mouse cortical neurons has been reported (Regueiro et al., 2015). In vitro studies have confirmed the genotoxicity and cytotoxicity of pyraclostrobin to human peripheral blood lymphocytes (Cayir et al., 2014). All of these studies suggested that the toxicity of strobilurins to organisms occurred via various routes.

\section{POSSIBLE PATHWAYS IN THE DEGRADATION OF STROBILURINS}

Complex structures of strobilurins provide several sites for metabolic reactions that follow multiple pathways. According to Balba (2007), the basic strobilurin degradation pathways involve methyl ester hydrolysis, ring hydroxylation followed by conjugation with glutathione or other biological groups, double bond biotic reduction and oxidation or photolytic reaction and isomerization to $Z$ isomer (Figure 2). The double bond of strobilurins in the acrylic moiety was noted to be vulnerable to various degradation mechanisms. These interactions are possible between the amino acids of the enzyme's active sites and the chemical bond of pesticides. Bauer et al. (2018) detected phase II metabolites of azoxystrobin in Brassica species by liquid chromatography and proposed its biotransformation pathway (Figure 3). They indicated that two main groups are separated in the initially activated phase I metabolites and conjugated phase II metabolites, and they were mostly formed via dealkylation reactions. Zhang et al. (2011) found an unexpected hydrolysis product, 3,3-dimethoxy-2-(2(6-methoxy pyrimidin-4-yloxy)phenyl) propanoic acid, during the hydrolysis reaction of azoxystrobin in methanol. In this hydrolysis, the cyano-benzene ring in azoxystrobin is substituted by methoxy and an acrylate double bond is added by methanol (Figure 4). Azoxystrobin acid is the major product in the normal hydrolysis reaction.

Lagunas-Allué et al. (2012) explored the photocatalytic degradation of pyraclostrobin in the presence of titanium dioxide $\left(\mathrm{TiO}_{2}\right)$ as a photocatalyst and UV light irradiation. The photodegradation pathway included the rupture of the phenyl bond and pyrazol, scission of oxygen, substitution of a chloride atom by the hydroxyl group, and hydroxylation of aromatic rings (chloro-phenyl, phenyl, and pyrazol) followed by the loss of the $N$-methoxy group (Figure 5; Lagunas-Allué et al., 2012). Adachi et al. (2018) investigated the mandestrobin photodegradation process in synthetic humic water (SHW) and buffered aqueous solution under continuous irradiation of artificial sunlight $(\lambda>290 \mathrm{~nm})$ (Figure 6). Homolytic bond cleavage at the benzyl phenyl ether of mandestrobin proceeded preferentially under direct photolysis, and photoClaisen rearrangement products were formed by the subsequent recombination of geminate radicals in a solvent cage. They also reported that the formation of a benzyl alcohol derivative was enhanced by the photosensitized generation of hydroxyl radicals in water. The photolysis products were finally degraded and mineralized to carbon dioxide (Adachi et al., 2018).

Wang et al. (2018) investigated the degradation pathway of benzene kresoxim-methyl (BKM) in aerobic soils (Figure 7). As shown in Figure 7, the BKM degradation process occurs via multiple parallel reactions, including (1) oxidative cleavage of the acrylate double bond or hydroxylation to yield BKMenol; (2) hydrolysis of the methyl ester or dealkylation; (3) further metabolism of the intermediates, such as oxidative cleavage and decarboxylation; and (4) cleavage of the ether linkage between dimethyl benzene and the phenylacrylate ring of BKM. Similarly, Romeh (2017) found that azoxystrobin also metabolized to azoxystrobin-enol in Plantago major. A similar degradation process was also discovered in trifloxystrobin, which forms a major metabolite of trifloxystrobin acid in plant materials (Liu et al., 2011). These results confirmed the basic 
degradation pathways of strobilurins that were identified and summarized by Balba (2007).

\section{MICROBIAL DEGRADATION OF STROBILURINS}

Microbial degradation is considered as the most significant pathway for strobilurin removal (Bacmaga et al., 2015; Chen et al., 2018). Hitherto, several strobilurin-degrading microbes have been isolated and include Bacillus, Pseudomonas, Klebsiella, Stenotrophomonas, Arthrobacter, Rhodanobacter, Cupriavidus, and Aphanoascus (Lopes et al., 2010; Clinton et al., 2011; Howell et al., 2014; Bacmaga et al., 2015; Chen et al., 2018). Documented strobilurin-degrading strains are listed in Table $\mathbf{1 .}$ A Klebsiella strain 1805 isolated from soil presented valuable attributes for the degradation of pyraclostrobin and triazole fungicide epoxiconazole (Lopes et al., 2010). Clinton et al. (2011) reported that four different species (Stenotrophomonas maltophilia, Bacillus amyloliquefaciens, Bacillus flexus, and Arthrobacter oxydans) isolated from soil could use trifloxystrobin as a carbon source; however, they failed to isolate azoxystrobindegrading bacteria. Howell et al. (2014) followed the sequential soil and liquid culture enrichment technique to isolate two bacterial strains (Cupriavidus sp. CCH2 and Rhodanobacter sp. $\mathrm{CCH} 1$ ) that use azoxystrobin as a sole carbon and nitrogen source. In the presence of an additional nitrogen source, both isolates also partially degraded other strobilurins, such as trifloxystrobin, pyraclostrobin and kresoxim-methyl. Four species of Bacillus spp. and two species of Aphanoascus spp. isolated from contaminated soil also survived on a high dose of azoxystrobin (22.50 mg. $\mathrm{kg}^{-1}$ ) (Bacmaga et al., 2015). In addition, two microbial communities (HI2 and HI6) capable of catabolizing pyraclostrobin as a sole carbon and nitrogen source were obtained from Hawaiian soils by Chen et al. (2018). Taxonomic identification showed that Pseudomonas was the dominant bacteria in both HI2 and HI6 microbial communities.

Among strobilurin-degrading microbes, including bacteria and fungi, bacteria play the most critical role. The long-term application of strobilurins affects microbial counts and microbial biodiversity in ecosystems. Due to the unique mechanism of action, strobilurins may directly affect fungal biomass by inhibiting mitochondrial respiration, which can induce a shift from fungal to bacterial dominance in soil activities (Adetutu et al., 2008; Bacmaga et al., 2015). For instance, the significant biodegradation of the parent azoxystrobin occurs within 21 days, even in the absence of light, which can reduce fungal diversity in soil. This group of chemicals inhibited the growth and development of fungi, whereas bacterial diversity remained unaffected under the same conditions (Adetutu et al., 2008).

Generally, degrading enzymes, especially esterase, occupy an important place in the process of ester containing pesticide biodegradation (Chen et al., 2014, 2015; Zhan et al., 2018a, 2020; Bhatt et al., 2019b, 2020). Chen et al. (2018) proposed the metabolic mechanism of pyraclostrobin biodegradation. As illustrated in Figure 8, pyraclostrobin detoxification was facilitated by carbamate hydrolysis, in which the tertiary amine

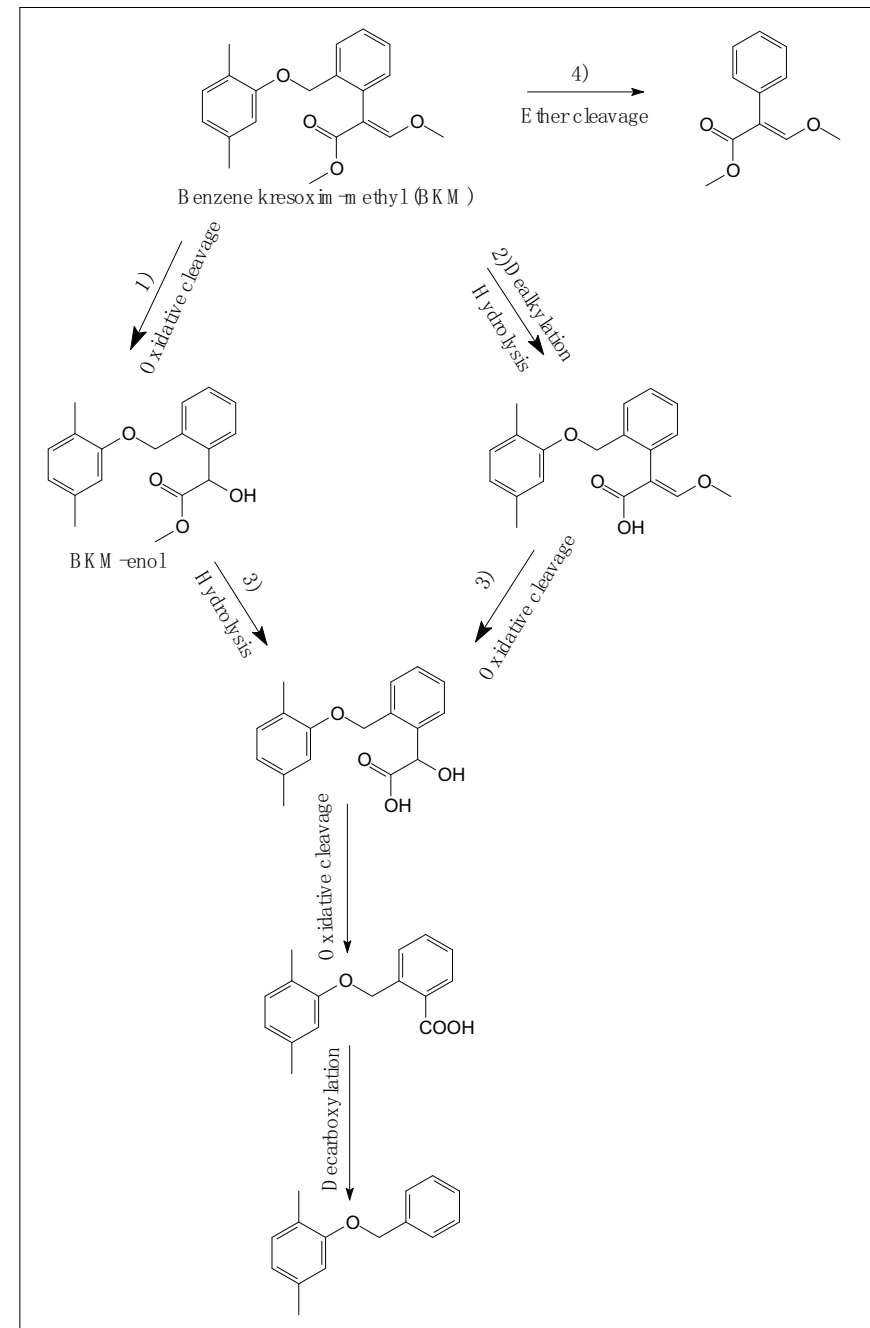

FIGURE 7 | Proposed degradation pathways of benzene kresoxim-methyl (BKM) in aerobic soils (based on Wang et al., 2018).

group of pyraclostrobin was decarboxylated and hydrolyzed to the primary amine group. The metabolic mechanism also indicated that carboxylesterase plays a key role in pyraclostrobin biodegradation. Though the structures of strobilurins were complex due to many active sites on its molecular, the possible molecular mechanisms involved in strobilurin biodegradation pathways were similar (Balba, 2007; Chen et al., 2018; Wang et al., 2018). It was generally regarded that the carboxylester hydrolysis via esterase was the primary degradation mechanism of strobilurins in microorganisms (Balba, 2007; Chen et al., 2018). Hitherto, a few studies have focused on strobilurindegrading enzymes. For instance, Katagi (2006) found that microbial degradation of azoxystrobin occurs by the hydrolysis of carboxyl ester bonds, indicating the central role of esterase in strobilurin degradation. Similarly, Chen et al. (2018) also inferred that carboxylesterase might be beneficial to the detoxification of pyraclostrobin. However, information regarding the degradation mechanisms of strobilurins is still insufficient. Previous studies observed that strobilurin metabolites were even more persistent 
TABLE 1 | Strobilurin-degrading microbes and microbial communities.

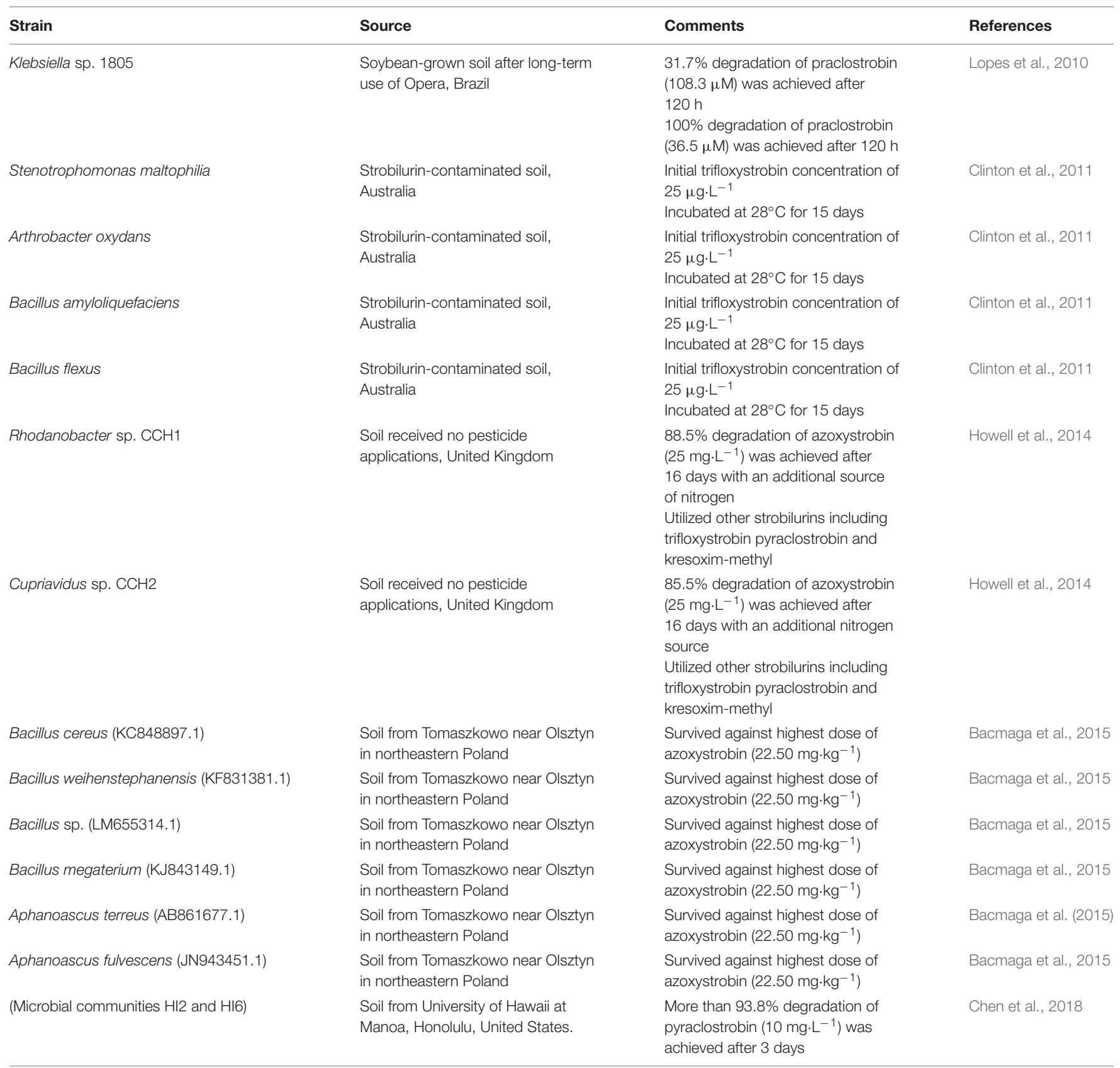

and toxic in the environment than the parent compound (Ghosh and Singh, 2009; Khandelwal et al., 2014). Thus, deeper insights into the possible molecular mechanisms of these pesticides and their eventual fate are indispensable.

\section{BIOREMEDIATION POTENTIAL OF STROBILURIN-DEGRADING MICROORGANISMS}

The accumulation of toxic and carcinogenic environmental pollutants, such as pesticides, plastics, dyes and other hydrocarbon-containing substances, is hazardous to ecosystems (Wasilkowski et al., 2012; Morillo and Villaverde, 2017; Huang et al., 2019). Thus, the development of a quick, easily applied, socially acceptable and eco-friendly approach against these xenobiotic compounds, such as enzyme-based bioremediation, is necessary (Karigar and Rao, 2011; Liu et al., 2015; Sharma et al., 2018; Zhan et al., 2018b). Microorganisms have the potential to degrade the toxic pesticides easily through their metabolic pathways (Bhatt et al., 2019b). Various universal and specific metabolic pathways participated in strobilurin degradation. During biodegradation processes, pesticides induce the expression of genes and enzymes that are upregulated under 


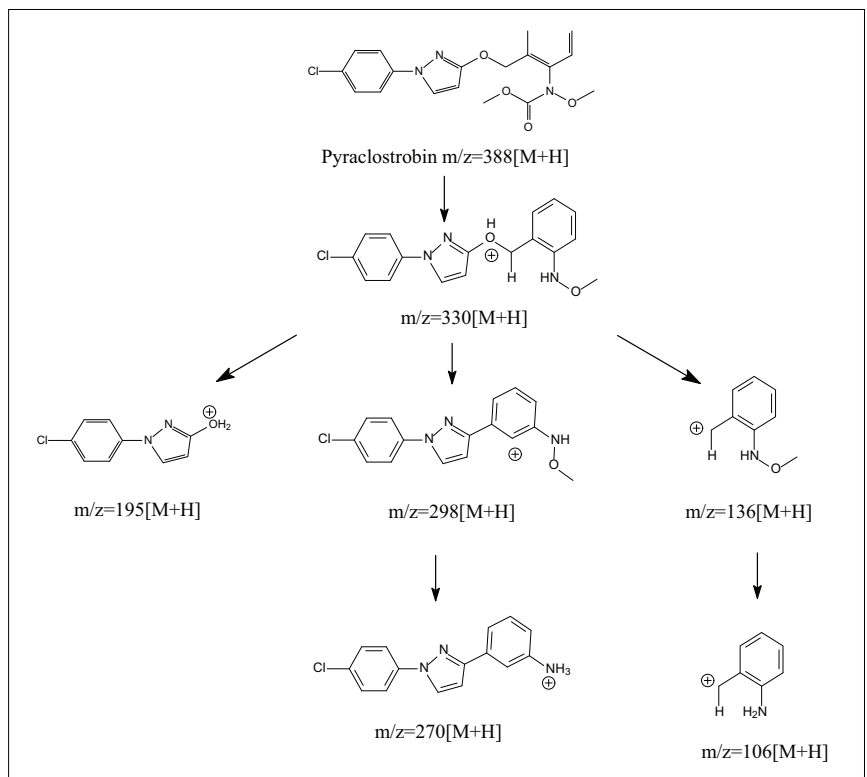

FIGURE 8 | Proposed metabolic mechanisms of pyraclostrobin in microorganisms (based on Chen et al., 2018).

stress conditions (Gangola et al., 2018; Bhatt et al., 2019a,b; Lin et al., 2020). Hence, it is crucial to isolate specialized microbial strains, as well as the efficient degrading enzymes and correlated genes, to accelerate the degradation rate and mineralization of strobilurins in contaminated soil/water environments.

Soil microbes exhibited bioremediation potential of strobilurin-contaminated environments. According to Liu et al. (2014), the degradation and mineralization process of a newly developed strobilurin fungicide (SYP-3343) was affected and accelerated by soil microbes. Zhao et al. (2017) explored the kinetic fate of BKM in aerobic soils and suggested that the soil type and microbial community composition controlled the process of BKM degradation and mineralization. Soil microbes can sharply decrease the residues of BKM as well. The persistence of strobilurins in soil varies from days to months at up to $50 \%$ degradation (DT50), depending on the soil microbial and chemical properties (British Crop, and Protection Council, 2009; Ghosh and Singh, 2009; EFSA, 2010). In addition, factors such as temperature, $\mathrm{pH}$, initial strobilurin concentration, nutrients and additional carbon sources affect the biodegradation process in soil (Chen et al., 2012, 2013; Cycoń and Piotrowska-Seget, 2016). The most desirable candidates for strobilurin biodegradation are microorganisms that are active under various environmental conditions and can degrade a wide range of strobilurins. It is also necessary to study the complex behavior of microbial communication networks, which play a decisive role in the microbes' adaptation to pollutants (Sharma et al., 2018). Azoxystrobin degrading potential of Arthrobacter, Mycobacterium, and Rhodococcus reported and correlated with increase and decrease of soil microbial community in combination of antibiotics. Metagenomics study suggested that some of the soil microbial genera significantly decreased (Proteobacteria and Firmicutes) whereas abundance of other like Actinobacteria increased in presence of strobilurins (Han et al., 2019). After soil applications strobilurins can reach the groundwater but the soil microorganisms have the potential to degrade them and reduce their effect in water system (Guo et al., 2017). Additionally, as the degradation of contaminants by microorganisms is a slow process, more details about strobilurin biodegradation pathways, degradation enzymes and genes that encode for key enzymes will help to identify the new bioremediation strategies.

\section{CONCLUSION AND FUTURE PERSPECTIVES}

The intensive/large-scale application of strobilurins in agricultural fields has increased contamination of the surrounding soil/water environments. Strobilurin toxicity may result in ecosystem imbalance and food-web disruption. Strobilurin residues have increased in trophic level due to biomagnification; thus, the development of degradation technologies for these pesticides is necessary. Strobilurin phototransforms under sunlight via various mechanisms, and photochemical degradation is one of the most prevalent processes underlying strobilurin degradation in water. However, uncontrollable reaction conditions and inefficiency in cleaning the environment in situ make this process unsuitable for strobilurin residues. The microbial removal of strobilurin contaminations from the environment is an efficient and cost-effective alternative approach. Therefore, the potential of strobilurin-degrading microorganisms and their enzymes should be studied. However, published literature about the use of microorganisms to bioremediate a strobilurin-contaminated environment is still insufficient. In addition, the efficient strobilurin-degrading enzymes and correlated genes in microorganisms, have not yet been investigated. Studies on cooperative degradation activities by microbial communities can help prevent the accumulation of toxic metabolites during degradation. Therefore, detailed foundation work should be accomplished before the field application of strobilurindegrading microorganisms is undertaken. The application of recently developed high throughput technologies for detecting strobilurin-degrading microbes in agricultural soil/water can generate better information about strobilurin degradation.

\section{AUTHOR CONTRIBUTIONS}

SC conceived of the presented idea. YF contributed to the writing and prepared the figures and tables. YH, HZ, PB, and SC participated in revising the manuscript. All authors approved it for publication.

\section{FUNDING}

We acknowledge the grants from the Key Area Research and Development Program of Guangdong Province 
(2018B020206001), National Natural Science Foundation of China (31401763), and Guangdong Special Branch Plan for Young Talent with Scientific and Technological Innovation (2017TQ04N026).

\section{REFERENCES}

Adachi, T., Suzuki, Y., Nishiyama, M., Kodaka, R., Fujisawa, T., and Katagi, T. (2018). Photodegradation of strobilurin fungicide mandestrobin in water. J. Agric. Food Chem. 66, 8514-8521. doi: 10.1021/acs.jafc.8b03610

Adetutu, E. M., Ball, A. S., and Osborn, A. M. (2008). Azoxystrobin and soil interactions: degradation and impact on soil bacterial and fungal communities. J. Appl. Microbiol. 105, 1777-1790. doi: 10.1111/j.1365-2672.2008. 03948.x

Anke, T., Oberwinkler, F., Steglich, W., and Schramm, G. (1977). The strobilurinsnew antifungal antibiotics from the basidiomycete Strobilurus tenacellus (Pers. ex Fr.) Sing. J. Antibiot. 30, 806-810. doi: 10.7164/antibiotics.30.806

Arora, P. K., Srivastava, A., Garg, S. K., and Singh, V. P. (2017). Recent advances in degradation of chloronitrophenols. Bioresour. Technol. 250, 902-909. doi: 10.1016/j.biortech.2017.12.007

Bacmaga, M., Kucharski, J., and Wyszkowska, J. (2015). Microbial and enzymatic activity of soil contaminated with azoxystrobin. Environ. Monit. Asses. 187, 615-629. doi: 10.1007/s10661-015-4827-5

Balba, H. (2007). Review of strobilurin fungicide chemicals. J. Environ. Sci. Heal. B 42, 441-451. doi: 10.1080/03601230701316465

Bartett, D. W., Clough, J. M., Godfrey, C. R. A., Godwin, J. R., Hall, A. A., Heaney, S. P., et al. (2001). Understanding the strobilurin fungicides. Pestic. Outlook. 12, 143-148. doi: 10.1039/b106300f

Bartlett, D. W., Clough, J. M., Godwin, J. R., Hall, A. A., Hamer, M., and ParrDobrzanski, B. (2002). The strobilurin fungicides. Pest Manag. Sci. 58, 649-662. doi: $10.1002 /$ ps.520

Battaglin, W. A., Sandstrom, M. W., Kuivila, K. M., Kolpin, D. W., and Meyer, M. T. (2011). Occurrence of azoxystrobin, propiconazole, and selected other fungicides in US streams, 2005-2006. Water Air Soil Pollut. 218, 307-322. doi: 10.1007/s11270-010-0643-2

Bauer, A., Luetjohann, J., Hanschen, F. S., Schreiner, M., Kuballa, J., Jantzen, E., et al. (2018). Identification and characterization of pesticide metabolites in Brassicaspecies by liquid chromatography travelling wave ion mobility quadrupoletime-of-flight mass spectrometry (UPLC-TWIMSQTOF-MS). Food Chem. 244, 292-303. doi: 10.1016/j.foodchem.2017. 09.131

Bending, G. D., Lincoln, S. D., and Edmondson, R. N. (2006). Spatial variation in the degradation rate of the pesticides isoproturon, azoxystrobin and diflufenican in soil and its relationship with chemical and microbial properties. Environ. Pollut. 139, 279-287. doi: 10.1016/j.envpol.2005.05.011

Bhatt, P., Bhatt, K., Huang, Y., Lin, Z., and Chen, S. (2020). Esterase is a powerful tool for the biodegradation of pyrethroid insecticides. Chemosphere 244:125507. doi: 10.1016/j.chemosphere.2019.125507

Bhatt, P., Gangola, S., Chaudhary, P., Khati, P., Kumar, G., and Sharma, A. (2019a). Pesticide induced up-regulation of esterase and aldehyde dehydrogenase in indigenous Bacillus spp. Bioremedit. J. 23, 42-52. doi: 10.1080/10889868.2019. 1569586

Bhatt, P., Huang, Y., Zhan, H., and Chen, S. (2019b). Insight into microbial applications for the biodegradation of pyrethroid insecticides. Front. Microbiol. 10:1778. doi: 10.3389/fmicb.2019.01778

Bony, S., Gillet, C., Bouchez, A., Margoum, C., and Devaux, A. (2008). Genotoxic pressure of vineyard pesticides in fish: field and mesocosm surveys. Aquat. Toxicol. 89, 197-203. doi: 10.1016/j.aquatox.2008.06.017

Boudina, A., Emmelin, C., Baaliouamer, A., Païssé, O., and Chovelon, J. M. (2007). Photo-chemical transformation of azoxystrobin in aqueous solutions. Chemosphere 68, 1280-1288. doi: 10.1016/j.chemosphere.2007.01.051

British Crop, and Protection Council, (2009). "Section 2: pesticides profiles," in The UK Pesticide Guide 21st Edition 2008, ed. R. Whitehead, (Wallingford: CABI Publishing), 90-97.

Cayir, A., Coskun, M., and Coskun, M. (2014). Micronuclei, nucleoplasmic bridges, and nuclear buds induced in human lymphocytes by the fungicide signum

\section{ACKNOWLEDGMENTS}

The authors are thankful to the entire globe researcher for their contribution.

and its active ingredients (boscalid and pyraclostrobin). Environ. Toxicol. 29, 723-732. doi: 10.1002/tox.21789

Chastain, J., Halle, A. T., Claire, P. D. S., Voyard, G., Traikïa, M., and Richard, C. (2013). Phototransformation of azoxystrobin fungicide in organic solvents. photoisomerization vs photodegradation. Photochem. Photobiol. Sci. 12, 20762083. doi: 10.1039/c3pp50241d

Chen, S., Chang, C., Deng, Y., An, S., Dong, Y. H., Zhou, J., et al. (2014). Fenpropathrin biodegradation pathway in Bacillus sp. DG-02 and its potential for bioremediation of pyrethroid-contaminated soils. J. Agric. Food. Chem. 62, 2147-2157. doi: 10.1021/jf404908j

Chen, S., Deng, Y., Chang, C., Lee, J., Cheng, Y., Cui, Z., et al. (2015). Pathway and kinetics of cyhalothrin biodegradation by Bacillus thuringiensis strain ZS-19. Sci. Rep. 5:8784. doi: 10.1038/srep08784

Chen, S., Dong, Y. H., Chang, C., Deng, Y., Zhang, X. F., Zhong, G., et al. (2013). Characterization of a novel cyfluthrin-degrading bacterial strain Brevibacterium aureum and its biochemical degradation pathway. Bioresour. Technol. 132, 16-23. doi: 10.1016/j.biortech.2013.01.002

Chen, S., Geng, P., Xiao, Y., and Hu, M. (2012). Bioremediation of $\beta$-cypermethrin and 3-phenoxybenzaldehyde contaminated soils using Streptomyces aureus HP-S-01. Appl. Microbiol. Biotechnol. 94, 505-515. doi: 10.1007/s00253-0113640-5

Chen, S., Hu, M., Liu, J., Zhong, G., Yang, L., Rizwan-ul-Haq, M., et al. (2011). Biodegradation of beta-cypermethrin and 3-phenoxybenzoic acid by a novel Ochrobactrum lupini DG-S-01. J. Hazard. Mater. 187, 433-440. doi: 10.1016/ j.jhazmat.2011.01.049

Chen, X., He, S., Liang, Z., Liu, Q. X., Yan, H., Hu, J., et al. (2018). Biodegradation of pyraclostrobin by two microbial communities from hawaiian soils and metabolic mechanism. J. Hazard. Mater. 354, 225-230. doi: 10.1016/j.jhazmat. 2018.04.067

Clinton, B., Warden, A. C., Haboury, S., Easton, C. J., Kotsonis, S., Taylor, M. C., et al. (2011). Bacterial degradation of strobilurin fungicides: a role for a promiscuous methyl esterase activity of the subtilisin proteases? Biocatal. Biotransfo. 29, 119-129. doi: 10.3109/10242422.2011.578740

Cycoń, M., Mrozik, A., and Piotrowska-Seget, Z. (2017). Bioaugmentation as a strategy for the remediation of pesticide-polluted soil: a review. Chemosphere 172, 52-71. doi: 10.1016/j.chemosphere.2016.12.129

Cycoń, M., and Piotrowska-Seget, Z. (2016). Pyrethroid-degrading microorganisms and their potential for the bioremediation of contaminated soils: a review. Front. Microbiol. 7:1463. doi: 10.3389/fmicb.2016.01463

Deb, D., Engel, B. A., Harbor, J., Hahn, L., Lim, K. J., and Zhai, T. (2010). Investigating potential water quality impacts of fungicides used to combat soybean rust in Indiana. Water Air Soil Pollut. 207, 273-288. doi: 10.1007/ s11270-009-0135-4

Dijksterhuis, J., van Doorn, T., Samson, R., and Postma, J. (2011). Effects of seven fungicides on non-target aquatic fungi. Water Air Soil Pollut. 222, 421-425. doi: $10.1007 / \mathrm{s} 11270-011-0836-3$

EFSA, (2010). Conclusions on the peer review of the pesticide risk assessment of the active substance azoxystrobin. EFSA J. 8, 1542-1652. doi: 10.2903/j.efsa.2010. 1542

FAO Meeting, (2008). Azoxystrobin: Evaluation of Data for Acceptable Daily Intake and Acute Dietary Intake for Humans, Maximum Residue Levels and Supervised Trial Median Residue Values. Available online at: http://www.fao.org/fileadmin/templates/agphome/documents/Pests Pesticides/JMPR/Evaluation08/Azoxystrobin.pdf

Fisher, N., Brown, A. C., Sexton, G., Cook, A., Windass, J., and Meunier, B. (2004). Modeling the Qo site of crop pathogens in Saccharomyces cerevisiae cytochrome b. Eur. J. Biochem. 271, 2264-2271. doi: 10.1111/j.1432-1033.2004.04169.x

Friberg-Jensen, U., Nachman, G., and Christoffersen, K. S. (2010). Early signs of lethal effects in Daphnia magna (branchiopoda, cladocera) exposed to the insecticide cypermethrin and the fungicide azoxystrobin. Environ. Toxicol. Chem. 29, 2371-2378. doi: 10.1002/etc.290 
Gangola, S., Sharma, A., Bhatt, P., Khati, P., and Chaudhary, P. (2018). Presence of esterase and laccase in Bacillus subtilis facilitates biodegradation and detoxification of cypermethrin. Sci. Rep. 8:12755. doi: 10.1038/s41598-01831082-5

Ghosh, R. K., and Singh, N. (2009). Effect of organic manure on sorption and degradation of azoxystrobin in soil. J. Agric. Food Chem. 57, 632-636. doi: $10.1021 /$ jf802716f

Guo, M., Wu, W. Z., Zhang, S. H., Song, N. H., and Shi, L. L. (2017). Degradation and adsorption of 2 kinds of strobilurin fungicides in soils and their effects on groundwate. J. Ecol. Rural Environ. 33, 460-465. doi: 10.11934/j.issn.1673-4831. 2017.05.011

Han, L., Liu, Y., Fang, K., Zhang, X., Liu, T., Wang, F., et al. (2019). Azoxystrobin dissipation and its effect on soil microbial community structure and function in the presence of chlorothalonil, chlortetracycline and ciprofloxacin. Environ. Pollut. 257:113578. doi: 10.1016/j.envpol.2019.113578

Han, Y., Zhu, L., Wang, J., Wang, J., Xie, H., and Zhang, S. (2014). Integrated assessment of oxidative stress and DNA damage in earthworms (Eisenia fetida) exposed to azoxystrobin. Ecotoxicol. Environ. Saf. 107, 214-219. doi: 10.1016/j. ecoenv.2014.06.006

Harms, H., Schlosser, D., and Wick, L. Y. (2011). Untapped potential: exploiting fungi in bioremediation of hazardous chemicals. Nat. Rev. Microbiol. 9, 177192. doi: 10.1038/nrmicro2519

Hnátová, M., Gbelská, Y., Obernauerová, M., Subíková, V., and Subík, J. (2003). Cross-resistance to strobilurin fungicides in mitochondrial and nuclear mutants of Saccharomyces cerevisiae. Folia Microbiol. 48, 496-500. doi: 10.1007/ bf02931331

Howell, C. C., Semple, K. T., and Bending, G. D. (2014). Isolation and characterisation of azoxystrobin degrading bacteria from soil. Chemosphere 95 , 370-378. doi: 10.1016/j.chemosphere.2013.09.048

Huang, Y., Zhan, H., Bhatt, P., and Chen, S. (2019). Paraquat degradation from contaminated environments: current achievements and perspectives. Front. Microbiol. 10:1754. doi: 10.3389/fmicb.2019.01754

Isamu, Y., and Makoto, F. (2005). Recent topics on action mechanisms of fungicides. J. Pestic. Sci. 30, 67-74. doi: 10.1584/jpestics.30.67

Jia, W., Mao, L., Zhang, L., Zhang, Y., and Jiang, H. (2018). Effects of two strobilurins (azoxystrobin and picoxystrobin) on embryonic development and enzyme activities in juveniles and adult fish livers of zebrafish (Danio rerio). Chemosphere 207, 573-580. doi: 10.1016/j.chemosphere.2018. 05.138

Joseph, R. S. I. (1999). "Metabolism of azoxystrobin in plants and animals," in Pesticide Chemistry and Bioscience, The Food Environment Challenge, eds G. T. Brooks, and T. R. Roberts, (Cambridge: The Royal Society of Chemistry), 265-278. doi: 10.1533/9781845698416.6.265

Karigar, C. S., and Rao, S. S. (2011). Role of microbial enzymes in the bioremediation of pollutants: a review. Enzym. Res. 7:805187. doi: 10.4061/ $2011 / 805187$

Katagi, T. (2006). Behaviour of pesticides in water-sediment systems. Rev. Environ. Contam. Toxicol. 187, 133-251. doi: 10.1007/0-387-32885-8_4

Khandelwal, A., Gupta, S., Gajbhiye, V. T., and Varghese, E. (2014). Degradation of kresoximmethyl in soil: impact of varying moisture, organic matter, soil sterilization, soil type, light and atmospheric CO2 level. Chemosphere 111, 209-217. doi: 10.1016/j.chemosphere.2014.03.044

Khandelwal, A., Gupta, S., Gajbhiye, V. T., and Varqhese, E. (2016). Degradation of kresoxim-methyl in water: impact of varying $\mathrm{pH}$, temperature, light and atmospheric CO2 level. Bull. Environ. Contam. Toxicol. 96, 130-136. doi: 10. 1007/s00128-015-1627-0

Lagunas-Allué, L., Martínez-Soria, M. T., Sanz-Asensio, J., Salvador, A., Ferronato, C., and Chovelon, J. M. (2012). Degradation intermediates and reaction pathway of pyraclostrobin with TiO2 photocatalysis. Appl. Catal. B Environ. 11, 285-293. doi: 10.1016/j.apcatb.2011.12.015

Lee, P., Nicholls, P., and Plimmer, J. (1999). "Metabolic pathways of agrochemicals," in Part 2: Insecticides and Fungicides, eds T. Roberts and D. Hutson (Cambridge, UK: The Royal Society of Chemistry), 1327-1342. doi: 10.1039/978184755 1375

Li, D., Liu, M., Yang, Y., Shi, H., Zhou, J., and He, D. (2016). Strong lethality and teratogenicity of strobilurins on Xenopus tropicalis embryos: basing on ten agricultural fungicides. Environ. Pollut. 208, 868-874. doi: 10.1016/j.envpol. 2015.11.010
Lin, Z., Zhang, W., Pang, S., Huang, Y., Mishra, S., Bhatt, P., et al. (2020). Current approaches to and future perspectives on methomyl degradation in contaminated soil/water environments. Molecules 25:738. doi: 10.3390/ molecules 25030738

Liu, J., Chen, S., Ding, J., Xiao, Y., Han, H., and Zhong, G. (2015). Sugarcane bagasse as support for immobilization of Bacillus pumilus HZ-2 and its use in bioremediation of mesotrione-contaminated soils. Appl. Microbiol. Biotechnol. 99, 10839-10851. doi: 10.1007/s00253-015-6935-0

Liu, L., Jiang, C., Wu, Z. Q., Gong, Y. X., and Wang, G. X. (2013). Toxic effects of three strobilurins (trifloxystrobin, azoxystrobin and kresoxim-methyl) on mRNA expression and antioxidant enzymes in grass carp (Ctenopharyngodon idella) juveniles. Ecotoxicol. Environ. Saf. 98, 297-302. doi: 10.1016/j.ecoenv. 2013.10.011

Liu, X., Wang, X., Xu, J., Dong, F., Song, W., and Zheng, Y. (2011). Determination of tebuconazole, trifloxystrobin and its metabolite in fruit and vegetables by a Quick, Easy, Cheap, Effective, Rugged and Safe (QuEChERS) method using gas chromatography with a nitrogen-phosphorus detector and ion trap mass spectrometry. Biomed. Chromatogr. 25, 1081-1090. doi: 10.1002/bmc. 1575

Liu, X. Y., Chen, X., Wang, H. Y., Ye, Q. F., and Ding, X. C. (2014). Dynamic characteristics of the novel strobilurin fungicide SYP-3343 in aerobic soils. J. Agric. Food Chem. 62, 3343-3347. doi: 10.1021/jf500392d

Lopes, F. M., Batista, K. A., Batista, G. L., Mitidieri, S., Bataus, L. A., and Fernandes, K. F. (2010). Biodegradation of epoxyconazole and piraclostrobin fungicides by Klebsiella sp. from soil. World J. Microbiol. Biotechnol. 26, 1155-1161. doi: 10.1007/s11274-009-0283-0

Morillo, E., and Villaverde, J. (2017). Advanced technologies for the remediation of pesticide-contaminated soils. Sci. Total Environ. 586, 576-597. doi: 10.1016/ j.scitotenv.2017.02.020

Mostafalou, S., and Abdollahi, M. (2013). Pesticides and human chronic diseases: evidences, mechanisms, and perspectives. Toxicol. Appl. Pharm. 268, 157-177. doi: 10.1016/j.taap.2013.01.025

Pearson, B. L., Simon, J. M., McCoy, E. S., Salazar, G., Fragola, G., and Zylka, M. J. (2016). Identification of chemicals that mimic transcriptional changes associated with autism, brain aging and neurodegeneration. Nat. Commun. 7:11173. doi: $10.1038 /$ ncomms11173

Piszczek, J., Pieczul, K., and Kiniec, A. (2017). First report of G143A strobilurin resistance in Cercospora beticola in sugar beet (beta vulgaris) in Poland. J. Plant. Dis. Protect. 125, 99-101. doi: 10.1007/s41348-017-0119-3

Reddy, S. N., Gupta, S., and Gajbhiye, V. T. (2013). Effect of moisture, organic matter, microbial population and fortification level on dissipation of pyraclostrobin in soils. Bull. Environ. Contam. Toxicol. 91, 356-361. doi: 10. 1007/s00128-013-1045-0

Regueiro, J., Olguín, N., Simal-Gándara, J., and Suñol, C. (2015). Toxicity evaluation of new agricultural fungicides in primary cultured cortical neurons. Environ. Res. 140, 37-44. doi: 10.1016/j.envres.2015.03.013

Rodrigues, E. T., Lopes, I., and Pardal, M. A. (2013). Occurrence, fate and effects of azoxystrobin in aquatic ecosystems: a review. Environ. Int. 53, 18-28. doi: 10.1016/j.envint.2012.12.005

Romeh, A. A. A. (2017). Phytoremediation of azoxystrobin and its degradation products in soil by P. major L. under cold and salinity stress. Pestic. Biochem. Physiol. 142, 21-31. doi: 10.1016/j.pestbp.2016.12.010

Sauter, H., Steglich, W., and Anke, T. (1999). Strobilurins: evolution of a new class of active substances. Angew. Chem. Int. Ed. 38, 1328-1349. doi: 10.1002/(SICI) 1521-3773(19990517)38:103.0.CO;2-1

Sharma, B., Dangi, A. K., and Shukla, P. (2018). Contemporary enzyme based technologies for bioremediation: a review. J. Environ. Manage. 210, 10-22. doi: 10.1016/j.jenvman.2017.12.075

Singh, N., Singh, S. B., Mukerjee, I., Gupta, S., Gajbhiye, V. T., Sharma, P. K., et al. (2010). Metabolism of 14C-azoxystrobin in water at different pH. J. Environ. Sci. Heal. B 45, 123-127. doi: 10.1080/03601230903471910

Walker, A. S., Auclair, C., Gredt, M., and Leroux, P. (2009). First occurrence of resistance to strobilurin fungicides in Microdochium nivale and Microdochium majus from French naturally infected wheat grains. Pest Manag. Sci. 65, 906915. doi: 10.1002/ps.1772

Wang, C., Wu, J., Zhang, Y., Wang, K., and Zhang, H. (2015). Field dissipation of trifloxystrobin and its metabolite trifloxystrobin acid in soil and apples. Environ. Monit. Assess. 187:4100. doi: 10.1007/s10661-014-4100-3 
Wang, L., Li, W., Li, P., Li, M., Chen, S., and Han, L. (2014). Residues and dissipation of trifloxystrobin and its metabolite in tomatoes and soil. Environ. Monit. Assess. 186, 7793-7799. doi: 10.1007/s10661-0143967-3

Wang, L., Zhao, J., Delgado-Moreno, L., Cheng, J., Wang, Y., Zhang, S., et al. (2018). Degradation and metabolic profiling for benzene kresoxim-methyl using carbon-14 tracing. Sci. Total Environ. 63, 1221-1229. doi: 10.1016/j. scitotenv.2018.05.123

Warming, T. P., Mulderij, G., and Christoffersen, K. S. (2009). Clonal variation in physiological responses of Daphnia magna to the strobilurin fungicide azoxystrobin. Environ. Toxicol. Chem. 28, 374-380. doi: 10.1897/08-279.1

Wasilkowski, D., Swedziol, Z., and Mrozik, A. (2012). The applicability of genetically modified microorganisms in bioremediation of contaminated environments. Chemik 66, 817-826.

Xiao, Y., Chen, S., Gao, Y., Hu, W., Hu, M., and Zhong, G. (2015). Isolation of a novel beta-cypermethrin degrading strain Bacillus subtilis BSF01 and its biodegradation pathway. Appl. Microbiol. Biotechnol. 99, 2849-2859. doi: 10. 1007/s00253-014-6164-y

Yang, J., Feng, Y., Zhan, H., Liu, J., Yang, F., Zhang, K., et al. (2018). Characterization of a pyrethroid-degrading Pseudomonas fulva strain P31 and biochemical degradation pathway of D-phenothrin. Front. Microbiol. 9:1003. doi: $10.3389 /$ fmicb. 2018.01003

Zeng, L. R., Shi, L. H., Meng, X. G., Xu, J., Jia, G. F., Gui, T., et al. (2019). Evaluation of photolysis and hydrolysis of pyraclostrobin in aqueous solutions and its degradation products in paddy water. J. Environ. Sci. Heal. B 54, 317-325. doi: 10.1080/03601234.2019.1571360

Zhan, H., Feng, Y., Fan, X., and Chen, S. (2018a). Recent advances in glyphosate biodegradation. Appl. Microbiol. Biotechnol. 102, 5033-5043. doi: 10.1007/ s00253-018-9035-0
Zhan, H., Huang, Y., Lin, Z., Bhatt, P., and Chen, S. (2020). New insights into the microbial degradation and catalytic mechanism of synthetic pyrethroids. Environ. Res. 182:109138. doi: 10.1016/j.envres.2020.109138

Zhan, H., Wang, H., Liao, L., Feng, Y., Fan, X., Zhang, L. H., et al. (2018b). Kinetics and novel degradation pathway of permethrin in Acinetobacter baumannii ZH-14. Front. Microbiol. 9:98. doi: 10.3389/fmicb.2018.00098

Zhang, J. G., Ruan, L. L., Zhao, J. H., and Zhu, G. N. (2011). An unexpected hydrolysis product from strobilurin fungicide: azoxystrobin. Chin. J. Struc. Chem. 30, 1132-1136. doi: 10.1021/om2006276

Zhao, J., Wang, L., Cheng, J., Wang, W., and Ye, Q. (2017). Fate characterization of benzene kresoxim-methyl (a strobilurin fungicide) in different aerobic soils. J. Environ. Qual. 46, 546-552. doi: 10.2134/jeq2016.08.0288

Zheng, D., and Köeller, W. (1997). Characterization of the mitochondrial cytochrome B gene from Venturia inaequalis. Curr. Genet. 32, 361-366. doi: 10.1007/s002940050289

Zubrod, J. P., Bundschuh, M., Arts, G., Brühl, C. A., Imfeld, G., Knäbel, A., et al. (2019). Fungicides: an overlooked pesticide class? Environ. Sci. Technol. 53, 3347-3365. doi: 10.1021/acs.est.8b04392

Conflict of Interest: The authors declare that the research was conducted in the absence of any commercial or financial relationships that could be construed as a potential conflict of interest.

Copyright (C) 2020 Feng, Huang, Zhan, Bhatt and Chen. This is an open-access article distributed under the terms of the Creative Commons Attribution License (CC BY). The use, distribution or reproduction in other forums is permitted, provided the original author(s) and the copyright owner(s) are credited and that the original publication in this journal is cited, in accordance with accepted academic practice. No use, distribution or reproduction is permitted which does not comply with these terms. 